\title{
Young Children's Use of Personalized Technologies: Insights From Teachers and Digital Software Designers in Japan
}

\author{
Natalia Kucirkova ${ }^{1}$ (D) Yuichi Toda $^{2} \cdot$ Rosie Flewitt $^{3}$ \\ Published online: 8 August 2020 \\ (C) The Author(s) 2020
}

\begin{abstract}
Many smart technologies offer personalized experiences, such as the possibility for children to record their voice, add their own pictures or drawings to digital stories, customize their avatars or adjust display settings to their needs. This study examined the views of teachers and digital software designers on children's use of smart personalized technologies in Japan. Sixteen teachers and two designers from Japan took part in semi-structured interviews on the school or company premises in Tokyo and Osaka. Thematic analysis of the transcripts yielded three themes: agency, privacy and autonomy, which we consider through the lens of socio-materiality. While there were clear concerns about the protection of children's privacy with personalized technologies, children's agency and autonomy in using them was perceived both as a benefit and limitation of digital personalization features. The participants' paradoxical perceptions of the risks and benefits of personalization point to a complex socio-technological model of personalization that is embedded in children's smart technologies and influences adults' views on their use in early education. Our findings have implications for informing and theorising the design of personalization features in digital technologies.
\end{abstract}

Keywords Early education $\cdot$ Technologies $\cdot$ Personalization $\cdot$ Tablets $\cdot$ Cross-cultural studies $\cdot$ Individualism $\cdot$ Socio-materiality $\cdot$ Japan

\section{Introduction}

National surveys, for example from USA (e.g. Common Sense Media Report 2017), UK (e.g. Ofcom 2018) and Canada (e.g. MediaSmarts 2012), have documented the trend for increasingly young children to spend more time using digital devices: an issue that has become a popular topic for scholarly debates, media attention and parental concerns. Given the ubiquity of technologies in children's lives, young children's technology use is not

Natalia Kucirkova

natalia.kucirkova@uis.no

1 Norwegian Centre for Learning Environment and Behavioural Research, University of Stavanger, NO-4036 Stavanger, Norway

2 Osaka Kyoiku University, Osaka, Japan

3 Manchester Metropolitan University, Manchester, UK 
so much an ideological question (e.g. are iPads good or bad for children's learning?) but rather a question about how technology connects with and is taken up in society and social practices (e.g. how can we optimize the design of technologies to engage families in couse of media?). In this paper, we develop a theoretical and empirical argument to explain some of the tensions in adults' views on learning technologies designed for young children. We report on a study that is nested in the socio-material theoretical tradition and provides detailed insights into personalization, which is a technology feature that is both socially and materially co-constructed.

\subsection{Theoretical Framework}

The conceptual framework that we bring to our research is socio-materiality. Socio-material theories are a set of theoretical perspectives that attend to the entangled social and material aspects - the 'assemblages' - that mutually shape all learning and being (Barad 2007). From a socio-material perspective, technologies are as much agentive, that is, capable of influencing decisions and changing status quo, as humans (Dezuanni 2015). Sociomaterial perspectives are considered within many theoretical orientations. Closest to our work is the socio-material theory in learning technologies, as proposed by Johri (2011a), who argues that 'socio-materiality can play a critical role by helping us overcome an inherent dualism in the learning technologies literature between the social implications of technology use and the material aspects of technology design' (p.210). We follow Johri's contention that a theoretical focus on socio-material assemblage enables the researcher to disentangle social and material issues, and to understand their complementarity and disjuncture (Johri 2011b). Socio-material approaches to the study of technologies emphasize the role of space in learning activities, which is understood as socially experienced and produced, with material qualities that are contributed by humans and the artefacts that humans use (Mitev and De Vaujany 2013). The use of personalized technologies is experienced and shaped by teachers and children in the space of their own culture(s) and in our case, the focus is on Japanese culture. In this study, our analytic gaze concentrated on the socio-material nature of personalized technology use and the ensembles of artefacts, culturally-situated social behaviours and people, in this case, teachers and children.

\subsection{Personalization and Personalized Technologies}

Personalization is an umbrella term that captures the possibilities of new media to be altered by individual users and tailored to individual users' personal needs, preferences and desires (Kalyanaraman and Sundar 2006; Dijkstra 2014). Personalization is an increasingly common phenomenon in digital technologies and a feature of societal change in the twentyfirst century (Hobbs 2020), but it is not bound to technologies: any practice or product that is tailored to an individual can count as personalized, including personalized education or personalized garments (Kucirkova 2017). With its emphasis on subjective and individualized experience, personalization weaves together several strands of the social fabric into a pattern that values individuality (see Kucirkova 2019 for a critique).

Personalization is an example of a socio-material feature that is reflected in the design of modern technologies, including personalized algorithms and personal mobile technologies. Personalized technologies actively solicit input from users and deploy personal data for improved functionalities, thus highlighting the intra-activity between humans and technologies (Barad 2007). Personalization is a rapidly developing research and innovation 
area, with many personalized resources offered to young children worldwide, including a booming personalized children's book industry (Picton 2017). A key feature of personalized resources is that they are either automatically or indirectly individualized. For example, users can insert their own voiceovers, photos, texts, name the tool and characters in games/stories, customize their avatars, choose their preferred settings and control the length and pace of their interaction with the tool. Personal mobile phone/tablet assistants, such as Siri ${ }^{\mathrm{TM}}$ or Alexa ${ }^{\mathrm{TM}}$, work with machine learning to individualize answers automatically. Personalized products and technologies are globally available, but their design corresponds to Western-centric values about the importance of individually-driven design that accommodates users' choices, preferences and control (Selwyn 2012). To date, very little is known about how personalized technology features are taken up in non-Western societies, or about how varied and sophisticated personalized technologies seep into the lives and learning of young children who are growing up in diverse socio-historical and cultural worlds. This is also an acute knowledge gap regarding the relationship between personalization and children's agency.

\subsection{Personalization and Children's Agency}

Agency has been noted as a defining feature of children's contemporary experiences with technologies that support children's own contributions and position them as active players or learners. Rowsell (2014) analyzed children's reading with iPads and concluded that in comparison with reading print books, individual child agency is heightened when reading with tablets, where children's reading tends to be action-oriented and ludic. Similar findings have been noted in children's learning and play experiences with video games (Domsch 2013), online games (Marsh 2011), Internet of Toys (that is, personalizeable smart toys) (Marsh 2017) and art-related apps (Marsh et al. 2018). Based on their observations of children (4-8-year-olds) using tablets in pre-schools, Fróes and Tosca (2017) coined the term "playful subversion" to capture children's agency in appropriating and playfully tinkering with tablets and apps. The more open-ended the design, the more options there are for the child's negotiation of their own meanings and construction of a unique, personalized experience - as shown also by Åberg et al. (2015) in their study of children's story-making with digital apps.

The early childhood literature pays considerable attention to the agentive and contentgenerative nature of modern technologies, which can be adjusted and modified according to individual children's preferences and learning needs. However, despite the rich observational data analyzed and theorized by researchers, personalization has rarely been a focus in interview and survey research. Informed by Johri's (2011a, b) socio-material framework that requires close consideration of both social and material influences, in this project we therefore purposively chose to investigate the social and material influences on technology use via interviews and survey instruments, focusing on teachers' and software designers' views and perspectives.

\subsection{Teachers' Views and Attitudes About Children's Technologies}

Research that documents teachers' views on children's use of technologies is important for two main reasons: firstly, while the presence of technology is ubiquitous, technology access in schools, where children spend a great deal of their waking lives, is mediated by their teachers and school staff. Teachers' attitudes towards technology are closely linked 
to their skills with technology and to societal values which shape the use of technology in the classroom (Chen and Chang 2006; Vidal-Hall et al. 2020). In addition, the relationship between technology use and curriculum requirements, school finances and technology purchasing power is an important consideration in teachers' views on technology use. Secondly, the research literature is clear that it is teachers' attitudes and perceptions, rather than their qualification, training, age or institutional factors, that shape teachers' pedagogy with technologies (see Mishra and Koehler 2006; Hedegaard 2009). Previous studies have examined teacher beliefs about the nature of children's learning with technologies and perceptions of their own digital competences (e.g., Krumsvik 2014), as well as the importance of teachers' views on children's access and use of technologies in classrooms (e.g., Neumann et al. 2018). Some studies combine interview data with observations of classroom practice. For example, Masoumi (2015) interviewed six pre-school teachers and observed their practice with technologies in Swedish pre-schools. The themes that emerged from these interviews indicated that the teachers perceived technologies as tools for communicating and documenting preschool practices but by and large, assigned the use of technology to supplementing existing activities.

In order to develop a deep understanding of teachers' views on the value of learning technologies for young children, we aimed to complement current literature with the focus on social and technological aspects of children's learning with personalized technologies. We were not interested in specific devices, such as iPads or whiteboards, but rather in the personalization features that are common to a variety of technologies. Our socio-material orientation implied a focus on the views not only of the technology mediators-teachersbut also of the technology creators-designers and programmers.

\subsection{Designers' Views and Attitudes About Children's Technologies}

One could say that digital software designers' views on children's learning are apparent in the products they make. For example, designers who follow the behaviorist design tradition tend to produce games and apps on the premise that children learn best through repetition and reward, and these products foreground individuals' responses to specific stimuli. In the learning technology literature, however, little is known about designers' own views on the technologies they design, let alone personalization. Even though there have been focused efforts to bridge the practice and design of children's technology (e.g., Garzotto 2008) and to bring teachers and designers into dialogue (Könings et al. 2014), very few studies (e.g., Könings et al. 2005) consider both the views of teachers and technology designers in their analyses.

In our previous project (Kucirkova and Flewitt 2020), we conducted focus group interviews with teachers and designers to compare their views on the benefits and limitations of personalization for young children's learning. We found significant discrepancies between teachers' and designers' views on personalization: the designers provided enthusiastic accounts of how personalization caters for 'magical' experiences that promote children's creativity and independence from a young age. In contrast, the interviewed teachers expressed concerns about personalized and personalizeable gadgets in terms of their absorbing and immersive effects on children and the negative consequences this may have for paying attention to adults' instruction. These views were expressed by British teachers and app designers/developers, all living and working in England. In British culture, individualism is highly valued, and is characterized by an acceptance of 'dissent, skepticism, lack of conformity, the ability to set rather than 
follow trends (e.g. in the creative industries) and individuality over the herd instinct' (Childs and Storry 2003, p. 21). With our socio-material orientation, we were interested in how cultural attitudes towards individuality and personal control play out in relation to personalization. In this study, we focused on teachers and designers from Japan. Japanese and British working practices are different and were found to persist even with Japanese companies operating in Britain (Tayeb 1994), with the British culture described as class-conscious but demonstrating solidarity with other workers across classes (Tayeb 2001). By contrast, Japanese culture is historically rooted in collectivist values.

\subsection{Individualism and Collectivism}

According to cross-cultural psychologists, individualism/collectivism is a dominant dimension when comparing cultures (Triandis 1995), although both occur across and within individual countries. Drawing on a body of cross-cultural studies (e.g. Gelfand et al. 2011), Triandis (2017) suggests that in collectivist cultures, people tend to define themselves by talking about relationships, while in individualist cultures they tend to talk about their own characteristics. In collectivist cultures, individual goals are consistent and relational to societal norms, while in individualist cultures, personal attitudes and idiosyncratic goals linked to personal satisfaction dominate. Although the collectivist/individualist dimension is a useful analytical tool, it would be difficult to describe an entire nation as either collectivist or individualist, particularly in the current highly mobile, diverse and globalized populations (Vignoles 2018). In our project, we did not follow a comparison that assumes a binary distinction of individualist versus collectivist cultures, but we explored the axis of this dimension in one culture. We chose the Japanese culture given its orientation towards collectivist values and a relatively high prevalence of personalized technologies such as personal robots among the wider population.

\subsection{The Japanese Culture}

Contemporary Japanese society subscribes to some individualist practices, such as valuing personal prestige, whilst also valuing collectivist principles, such as conformity and tradition (Mathews and White 2012). Ronald and Hirayama (2009) analyzed social change in post-war Japan in relation to an increase in individualism, and argue that Japanese children born in the 1970 s - the so-called lost generation — pay attention to their bodies, individual life trajectories and identities but remain true to collectivist values when it comes to work and social progress. With regard to Japanese attitudes and learning, Sato (2003, p. 2) suggests that Japanese culture 'emphasizes clear-cut distinctions between insiders and outsiders and between one's public and private face.' Li (2012) posits that the learning model in Western countries focuses on the self, while in Eastern countries, such as Japan, education foregrounds a collaborative approach to cultivate society and the self, body and mind. Landerholm (1996) cites a proverb that captures this attitude in many Japanese schools: 'the nail that sticks up is pounded down' (p. 33), implying that everyone should work for the common good and should not risk prioritizing their individuality. Considering these deeply rooted beliefs in Japanese culture, we were interested in gauging the attitudes of Japanese 
teachers and designers on personalizeable technologies, where individualism is pivotal to their design.

\subsection{Personalized Technologies in Japan}

Since the 1990s, Japanese society has adopted a vast array of technologies that are, or that can be, personalized (e.g., the Aibo ${ }^{\mathrm{TM}}$ and the humanoid robot ASIMO ${ }^{\mathrm{TM}}$ ). The robot Pepper $^{\mathrm{TM}}$ (designed by Softbank Ltd. in 2014) can hold a personal one-to-one conversation through artificial intelligence and is popular on the Japanese home market, together with LINE Ltd, whose smart speakers specifically target families and children. A survey by Video Research Interactive in May 2018 found that $9.4 \%$ of Japanese adults would like to purchase a smart speaker as the next electronic device (Zhang and Itoyama 2018), which indicates growing interest in personal voice assistants in Japan. For the school market, a leading company in educational technologies in Japan, Just Systems Ltd., has developed personalized education software, which according to the company data, was used by $85 \%$ of public elementary schools in Japan in 2019 (www.justsytems.com). Japanese Human-Computer Interaction researcher Sato (2008) developed, implemented and evaluated two personalized learning software products that enable children to create their own stories using their own audio-recordings, pictures and texts, either on their own or collaboratively with a peer or adult.

In addition to personalized software and apps, virtual and digital pets are highly popular in Japan. These can be programmed by their owners, and those that are enhanced with Artificial Intelligence can be taught to respond to the owner in a customized manner. With virtual pets, the owners assume avatar roles and interact with their pets online. Japanese people are known for their affection towards digital pets and the research and development of digital pets is a focus for tech development in Japan (e.g., Kanoh 2012; Yoshida et al. 2017). Cultural attitudes towards the socializing role of digital pets have been the focus for cross-cultural studies, such as Chesney et al.'s (2010) comparison of UK and Japanese adults' attitudes towards virtual pets, which found that the Japanese participants held a stronger bond of affection with virtual pets than their British counterparts.

In our review of literature related to this project, we did not identify any studies in English-speaking academic journals that included Japanese teachers' and designers' views on learning technologies more broadly, let alone personalized technologies more specifically, or personalized features in software for young children. Indeed, as Gromik (2009) pointed out, there is little in-depth evidence on the use of technologies in Japan, with most studies focused on student use of Internet-based software programs, particularly when studying English, in research that is often characterized by low reliability. Our study aim was to address this gap by informing and theorising the design and use of personalization features through the lens of socio-materiality.

\subsection{Aims and Objectives}

The study had two main objectives: the first was empirical and aimed to explore Japanese teachers' and designers' views on the personalization features of learning technologies for young children. The second was conceptual in nature and aimed to establish the connections between social and material aspects of personalization and their individualizing potential. Our focus was on learning technologies designed for children of pre-school 
(kindergarten) and primary school (elementary school) age, in both formal and informal learning environments. Inspired by Johri (2011a), the material aspects of our enquiry included technology design and use across time and space, while the social aspect included participants' values, views and perceptions of digital personalized stories. Our guiding research question was:

What insights can be gained from a socio-material approach to Japanese teachers' and designers' views about personalized technologies for young children?

\section{Methods}

Our empirical study involved focus group interviews with Japanese teachers and software designers and was informed by a socio-material theoretical framework and our review of relevant literature.

\subsection{Study Participants}

The study's convenience sample (see Etikan et al. 2016) consisted of sixteen teachers and two representatives of companies that design toys or digital games for families. The teacher sample comprised twelve female and two male trainee teachers and two female full-time teachers, who were interviewed in focus groups of three to four participants. The interviews were facilitated by the researchers, who encouraged the participants to share their views freely. One British teacher, who had worked in a Japanese kindergarten for the three years prior to the study, also took part. Given the focus on native Japanese teachers' views, this teacher's opinions were not analyzed as part of this study. The software design interviewees worked at major Japanese digital or toy companies and were interviewed on the company premises.

\subsection{Study Procedure}

The study was funded by the Daiwa UK-Japan Foundation, with a grant to the first author. The participants were all personally known to the second author and were selected on the basis of their availability, their experience of working in early or primary education and spoken knowledge of English. Authors 1 and 2 visited the two digital companies on their premises in Tokyo, where they spoke with the CEOs and were shown each company's product range. The directors for children's products were interviewed in a quiet room on the company premises. Interviews with the teachers took place on the Japanese University premises and one interview was conducted in a hotel café, which was more convenient for the participants. The interview questions were the same as those asked of UK teachers and producers in 2017 by Kucirkova and Flewitt (2020) and included a short video demonstration of the relevant technologies to facilitate understanding. The videos showed personalized books and AI-enhanced smart toys that children or their parents/teachers can customize to their needs and personalize with their own voiceover and photographs. The first and second author were present during all interviews so simultaneous translation could be offered when participants requested it. 


\subsection{Data Sources}

All interviews were conducted in English and were audio-recorded, with Japanese translation available for participants when needed. The interview length ranged from forty-nine minutes to two-and-half-hours, including translation time, so length is indicative; the shortest interview did not involve any translation. Interviews were conducted in focus groups, with only occasional prompts, used when necessary to keep the flow of talk on the chosen topic. There were seven focus-group interviews in total. In addition to audio-recordings, the researchers made fieldnotes and used these to support the data interpretation. The audio-recordings were transcribed by a UK-based, professional transcription service. The transcriber was instructed not to alter any expressions and to transcribe all participants' responses in English. The quotes included in the Findings section are unedited, although some include Author2's translation into English from the original Japanese, and these instances are indicated.

\subsection{Data Analysis}

The transcript data were analyzed qualitatively, using thematic analysis, as described by Boyatzis (1998), an approach that is suited to semi-structured interview data. Semi-structured interviews offered the advantage of extending the discussion by following up on issues of particular interest (Rubin and Rubin 2011). During thematic analysis, we developed codes that corresponded to the research questions, following three phases of "seeing", "encoding" and "interpreting", bearing in mind Aronson's (1995) pragmatic view that our final themes needed to align with both the research literature and participant feedback. We consulted with participants for their views on the themes, but no changes were recorded.

\subsection{Ethical Considerations}

Ethical permission was granted by the University College London, Institute of Education, Ethics Committee. Before signing the Consent forms, all teachers were informed about the study objectives, given the opportunity to ask questions and reassured they could withdraw from the study at any time, as outlined in the Information Leaflets, which were in Japanese. All interviews were held at times and locations that suited participants' schedules. Given the qualitative study design and our snowball sampling procedure that involved participants personally known to the second author, we engaged in extensive reflexivity to monitor and enhance the study rigour (Berger 2015). The end of the project included consultations with study participants and colleagues at the researchers' respective institutions to discuss and scrutinize initial findings. These are standard strategies in qualitative research to augment the validity of findings and interpretations (Dowling 2006; Yanow 2015).

\section{Findings}

Through iterative and conceptual theme development, three main higher-order themes were identified in the data: agency, privacy and autonomy. This section discusses these three themes, illustrated by relevant quotes from the interview data. The participants are referred to as T1-16 for the teachers, D1-2 for the designers and R1 or R2 for the first or second author who were present during all interviews. 


\subsection{Theme1: Agency}

Agency refers to the volitional choices that children make when interacting with tools, including digital technologies. For teacher participants, individual children's agency was essential for their technology use. Some of the interviewed teachers voiced the view that modern technologies are taking over from traditional non-digital play, and that children need to know how to use digital devices. They did not want children's play to be controlled by smart toys, but for children to be the agents of decision-making in their play. Nor did they want to lose control of personal data. A female teacher explained her view: 'I think it is necessary to know the toys connected to the Internet. I think that the world spreads out if there is technology that you can enjoy. However, I think that you must start using it, not being controlled by those toys'. T16.

Talking more broadly about the benefits and limitations of personalized smart toys that respond to the child and can sustain AI-powered conversations with children, different teachers had different views. One teacher (T1) mentioned that having a smart teddy bear was a "dream", explaining that when she was a child, she had imagined her teddy would talk back to her. For another teacher (T11), the Internet of Toys was a source of anxiety for parent-child relationships: 'if parents buy the teddy bears, parents won't do anything - they will just depend on the teddy bears.' (R2's translation of T11 viewpoint). The same concern was expressed by T14 in relation to teacher-child relationships: 'I think the most important thing is the relationship between the teacher and the children, so the teddy bear is not a good idea'.

When talking about personalized books and digital stories made by children, the teachers liked the idea of children making their own content, with or without the aid of digital technologies. As one designer explained, children's own story-making is linked to soft skills such as creativity and innovation:

The authoring or co-authoring of stories is very important in this respect. It also encourages their senses of imagination and creativity. D2

Similarly, the teachers emphasized the fun element of children making their own stories: 'It seems that they feel it is fun to write stories and their own dreams'. T16. This view prevailed, regardless of the format of children's stories (digital or on paper).

\subsection{Theme2: Privacy}

The interviewed teachers and designers spoke enthusiastically about children's use of technologies, especially in terms of the importance of nurturing children's future technical skills. However, when discussing personalized smart technologies, there was a strong concern among participants about the ways in which these technologies collect data about individual children. For example, when children personalize their digital stories or customize the behaviour of their smart toys by adding their own names, voiceovers, pictures or preferences to digital devices. The teacher participants had concerns about the integrity of technology companies' capacity and motivation to protect and safeguard their clients' personal data. As two female teachers asserted, personalization has many benefits, but data privacy is an issue that has not yet been fully addressed:

I think that will also be useful both at home and at kindergartens/school. However, from the viewpoint of protection of personal information, I think that it is difficult to choose how to record. T16 
I think that it is very advantageous to utilize children's own photos among family members, kindergartens and intimate people. Unfortunately, as material to be released to the outside world, I think that it is becoming very difficult recently from the viewpoint of protection of personal information. T13

Some teachers expressed the view that safeguarding children's digital data can be more problematic for schools, as teachers cannot simultaneously supervise all children's online activity, particularly when multiple devices are being used in class. This issue was also raised by one of the designers:

As monitoring use of digital technologies can be important, it may also be difficult to monitor large numbers of children of a young age. D1

Whereas teachers recognized the usefulness of personal mobile technologies for individualized instruction, they reported that children's online access tended to be more restricted in school than at home, where parents might be more able to supervise children's technology use:

... so in a family it's a very good idea, but so in school it's very sensitive, consid-

ering problems for the personal data. T5

One designer in this study reported diverse measures taken by his company to ensure that no personal information was revealed about users, including software that blurs images and can change the sound of a user's voice to minimize the possibility of user identification. To this designer, keeping data safe and anonymous seemed to be more important than preserving the creative value of original user production.

\subsection{Theme3: Autonomy}

During one of the interviews with teachers, the authors were introduced to personalized books made by children with Attention Deficit Hyperactivity Disorder (ADHD) or learning delay. The teachers explained that the children were encouraged to make their own books and were closely supported in a 1-2-1 session by a teacher in the classroom. One of the teachers brought such a self-made printed personalized book to the interview, which had been designed by a five-year-old child who had little spoken language. The book featured the child's favourite things, including: a colourful car on each page; a spaceman with a large head; and some people who the child described as his mother and himself (Fig. 1). The teacher reported that the child's mother cried with joy when they showed her the book and all the teachers were proud of the child having made the book entirely by himself.

The teacher emphasized the child's independent work on the book, its length and the choice of images and colours. Other teachers mentioned that in their classes, books were made by children's parents or teachers but not by the children themselves. One participant shared her experience of making a book for her cousin:

T3: Actually I'm working on ... want to do a book for children. My cousin can't speak so I made it for him.

R1: Uhuh. So that is a personalized book for your cousin.

T3 Yes. 
Fig. 1 The cover of the child's self-made book

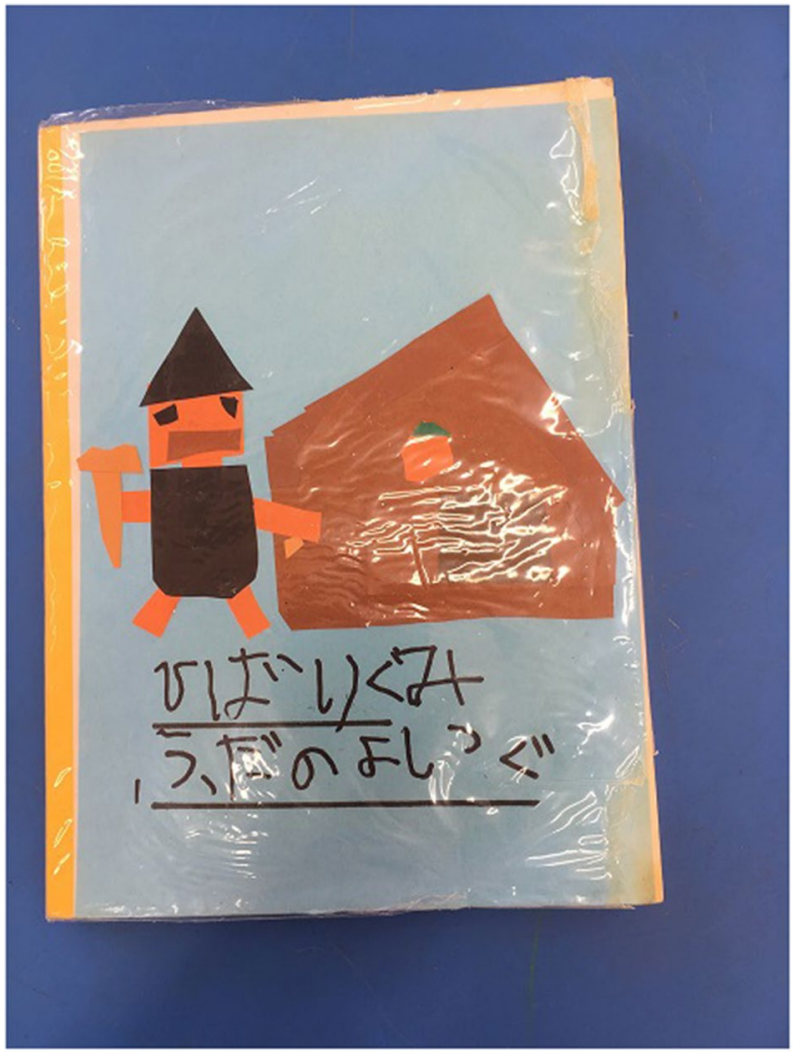

While almost all the participating teachers recognized the importance of children's own stories, there was no consensus on whether individual children's story-telling was appropriate in class. Teachers expressed a strong preference for classroom-based or family-oriented stories rather than stories centered around a single child. One teacher (T6) suggested making one personalized book per entire class. Two different teachers suggested each child might offer a chapter in a shared collective book, so that all children would be equally represented in a whole-class book. In addition to the social implications attributed to the value of a collective book, the teachers had reservations about the potential cost of producing individual personalized books, if produced in print form:

\section{T3 Um ... I will not buy for every children - some children. \\ $R \quad$ Only for some? \\ T3 It's very expensive.}

The teachers had further concerns about the practicalities of making a personalized book for each child in a kindergarten, and how much time it would take in a typical class of five-year-olds, where the average child-staff ratio is one of the highest internationally, 35 children to one member of staff (Taguma et al. 2012). In addition, given the Japanese system of classroom rotation, the teachers would need to create new books at the beginning of each school year when they were allocated to a new classroom. Teachers from one 
kindergarten mentioned that many years ago, they used to create personalized print-based books for all children in the class, using pictures, collages and colourful stationery, but this practice had been discontinued as it had been so time-consuming. One teacher in this kindergarten was interested in the possibility of making digital books and thus streamlining the story-making process. However, he expressed concern around time as well as children's potential dissatisfaction with self-produced digital stories:

... hearing one's own voice can often be jarring due to the perceived difference in sound, which may make some children dislike hearing themselves. It could also be very time consuming to record all children in a class. T7

In summary, whilst the participating teachers valued the autonomy offered to children with learning delay by the activity of making their own books, they identified diverse concerns about the practicalities and potential of personalized story making for typically developing children, and these concerns impeded their use in school.

A further concern regarding children's autonomy with personalizeable technologies related to their use in families, where parents might not have the financial resources or technical skills to support children. One designer (D2) agreed that not all parents would have the level of technical skill needed to program personalized toys, such as populating a programmable toy with their child's name, preferences and other data. Personalized toys therefore tended to be bought and used in more socially advantaged families, with 'high education parents [who can buy] the high expensive devices and give to them' [the children], D2.

Teachers were concerned about the lack of support for families about how to engage with and use the Internet of Toys, particularly in families with limited digital competence. One teacher was particularly anxious about wider family members, including grandparents, using smart toys with their grandchildren, fearing that grandparents would have more difficulties with technology than parents. There might therefore be issues of equity for children who are looked after by their grandparents, as the support they received for smart toys use might be of lower quality or non-existent: 'So when children live with their grandfathers can they ... I don't think that ... maybe they will refuse to use the toys.' T9.

\section{Discussion}

Our study findings indicate that Japanese teachers' and designers' views on personalized technologies were characterized by a recognition of both positive and negative aspects of digital personalization. The ambivalent nature of digital personalization draws attention to the dualism in technologies that was highlighted in Johri's socio-material theoretical analysis. It also corresponds to scholars' reflections on the ambivalent role of learning analytics in supporting real-time analysis and monitoring on the individual level, which have been highlighted as to produce both beneficial and potentially detrimental effects, such as increased motivation yet attention loss and/or classroom disturbance (Ifenthaler et al. 2014). All our participants valued the potential for parents and teachers to support children's agency by encouraging their purposeful use of personalized digital products, such as creating their own digital stories. However, they also recognized the risks posed to children's safety and security by the disclosure of personal information, the difficulty of ensuring the privacy of personal data, the time-consuming nature of working one-to-one with children in classes with low teacher: child ratios and the social inequity of children's 
access to personalized products and digital devices at home. There were therefore notable tensions in how the participants articulated the benefits and limitations of personalization for children's learning, as has recently been reported for older students (Fake and Dabbagh 2020). To better understand these tensions, we turned to sociomaterial theorization of participants' perspectives of the risks and benefits of personalization features in digital technologies, and their connections to the well-reported privacy paradox (Barnes 2006) and autonomy paradox (Mazmanian et al. 2013).

\subsection{Privacy Paradox}

The personalization privacy paradox refers to users' dilemma between sharing personal data on social networks while not wanting their personal data to be accessible to unknown others for their own purposes—such as for commercial interest (Barnes 2006; Awad and Krishnan 2006). Our study participants were enthusiastic about the material affordances offered by digital technology for children to make their own personalized digital stories, but they were concerned about the social consequences of how children's personal data might subsequently be (mis-)used. The pragmatic solution they offered during the focus group discussions was to restrict children's use of personalized digital products to the home where parents could more easily monitor their children's personal data disclosure. However, all participants recognized that this solution was far from ideal, as it would serve to perpetuate social inequity - given that some families would always have greater financial and digital skill capacity than others to support children's learning with personalized digital products.

Thus, there was a tension in views amongst participants between the material affordances of digital media and software to create individualized learning content and the potentially negative social consequences of personal data disclosure and deployment. The material aspects of personalized technologies were therefore identified as clashing with the social aspects of cyber security and data misuse.

\subsection{Autonomy Paradox}

The autonomy paradox refers to the tension between autonomy and privacy. For example, research into the use of emails on mobile devices suggests that users have greater freedom to choose when and where they work, yet this change in social practice has led to unprecedented collective expectations around individuals' perpetual availability for work (Mazmanian et al. 2013). On one hand, the user is autonomous and empowered, but on the other hand, the user is dependent and surveilled. This calls to mind Foucault's (2003) discussion of panoptic surveillance to describe how mechanisms of power are used to normalize and subjugate citizens in society. Digital technologies that collect and generate personal data offer the state and large EdTech companies the potential to extend the panoptic surveillance into everyday life. The intensive data analytics that are possible with personalized technologies give rise to what Knox et al. (2020) describe as "machine behaviourism" that undermines individuals' autonomy and participation in the learning process. With personalized software and apps, children are, in terms of the physical classroom space, working on their own, but their autonomy is undermined by a close monitoring system embedded in personalized apps that record every tap on the screen.

In our study, the teachers and designers reflected on the creative potential of children's independent creation of storybooks but on the other hand, they reported the need for close 
adult supervision of children's independent technology use. In a study with Korean preschool teachers, Kim (2004) found that although the teachers believed in the importance of fostering children's autonomy through child-driven activities, their practice was very much influenced by parents' expectations about teachers' support and direction. Given the lack of public funding for Korean kindergartens, Kim (2004) found that parents were perceived as key gatekeepers for children's learning, who were able to pay for digital resources, and this extended parents' direct influence on teaching content. Previous studies report that Japanese kindergarten teachers face similar pressures in their profession, given the high expectations of Japanese parents regarding their children's early education (see Izumi-Taylor et al. 2011).

\subsection{Cultural Issues and Individualism}

The findings from our small-scale study map onto the growing literature that argues against a cultural 'binary' between individualist and collectivist values and societies. Triandis (1990) distinguishes between individualism and collectivism to explain variance in social behaviour, and Triandis and Gelfand (1998) further break down the difference between individualism and collectivism into four categories of hierarchical and vertical values, corresponding to cultures that favour egalitarianism (horizontal) and competition (vertical cultures). Hierarchical individualist values are associated with self-reliance and the desire to be unique, while vertical individualist cultures are linked to competition and hedonism. The preference for children's agency, privacy and autonomy expressed by our participants could be considered to be aligned with the ideal of hierarchical individualist values. However, there was a striking contrast in the participants' views on individualist values: the teachers and designers talked about the importance of children's agency and autonomy in controlling the technologies they use, yet they did not yet articulate their own role in facilitating children's independent use of technologies in educational settings. Rather, all teacher participants focused on the challenges of monitoring children's technology use with regard to their professional duty to safeguard children's wellbeing. Furthermore, although the teachers highlighted the potentially damaging effect of personalized technologies on interactions in the classrooms and data misuse, they remained enthusiastic about the potential that digital personalization offered to stimulate children's creativity and imagination.

Thus, we found that within one culture, both individualist and collectivist values were present in adults' perspectives on personalization. As Lim and Torr (2008) propose, future research should attend to individual teachers' views on children's agency, both within and across cultures. We further argue that the design of culture-specific personalized technologies might make learning not only more effective (eg. Yau and Hristova 2018) but also more aligned with a nuanced view on personalization affordances. In particular, we suggest that a richer understanding of adults' views on personalized technologies could evolve from studying what we term the "agency paradox".

\subsection{Agency Paradox}

The teachers in our study were concerned about the difficulties of monitoring children's activity when using digital devices in their classrooms, and suggested that home might be a better place for children's online activity. However, they recognized that children have unequal access to digital resources and support at home. Teachers also identified the value of creating collective personalized books that would feature all children in the classroom, 
and the potential offered by digital technology and child-led story-making for children with complex learning needs. The study therefore found that teacher participants appreciated the benefits of personalized technology use for all children, yet practical considerations and concerns for children's safe use of online devices, including smart toys, led them to prioritize some children's access over others. We call this phenomenon the agency paradox and argue that in addition to the privacy and autonomy paradox, agency is a further dimension linked to personalization.

The agency paradox refers to the contrasting subjective and collective experience of individuals' agency. In early childhood literature this tension is recognized in child-centered education, where agency is recognized as both individual and collective. That is, individual children's needs and interests underpin child-centred pedagogy, which takes individual children's rights as citizens seriously (Gupta 2014), yet the relational nature of children's agency is equally emphasized by fostering children's collaboration and collective dispositions (Taylor 2013). Early education in Japan is geared towards developing individual children's potential (Tobin et al. 2009), but when compared with other countries, such as Sweden, for example, Japanese early education can be described as more led by adults than by children (see Carlsson et al. 1996). This was evident in our interview data when the teachers described book-making as an adult-driven activity. Landerholm's (1996) interviews with Japanese educators and parents of children attending special and mainstream early childhood education programs found anomalies between participants' views on childcentered curriculum ideals and the reality of everyday classroom management. A similar discrepancy between the vision and reality of teachers' practice was noted by Ishigaki (1991). There are several explanations for the differences in teachers' views on children's agency and their actual practice in early childhood classrooms. As Holloway (2013) rightly points out, attempting to identify a unified perspective on the philosophy of Japanese preschools is a flawed ambition, given the diversity of educational approaches adopted in different establishments, and the multiple influences of ideology, religion, social class of parents and state or private ownership of the pre-school as well as its physical location (rural versus urban). However, Japan's preschools are all part of a high-stakes accountability regime that relies on data to judge the quality of schools and to drive school development plans. This influences teachers' sense of accountability and how they structure children's activities, at times at the expense of foregrounding child choice and agency. These tensions are replicated in their perspectives on personalized digital devices.

In addition to the tension between teachers' views and practice concerning children's agency, there are tensions in their views and practice concerning their own agency. Kahn (2009) examined the agency of academics who were in the early stages of developing their teaching practice. Drawing on social realist theory, Kahn (2009) argues that teachers' attitudes towards their own agency and the socio-cultural structure are in tension. In our study, the teachers emphasized the importance of child agency, but also reported how this was constrained by the practicalities of accommodating individual children's needs in large classrooms. This discrepancy highlights the complementary and contrasting social and material dimensions of child agency. From a socio-material perspective, the non-human dimensions of space, such as the classrooms in which teachers mediate children's technology use, intra-act with humans and mutually constitute the reality faced by teachers and children alike (Kuby, 2017). The question for researchers, designers and teachers is how to make these spaces productive for 'new ways of knowing and understanding' (ibid, p.881).

However, our findings suggest that for practitioners, rather than offering new ways to enhance children's agency, digital technologies exacerbate the agency paradox, particularly for children whose parents and caregivers do not have the financial or knowledge resources 
to support children's digital device use. In many European countries, parents often restrict their children's agentic use of technologies (Livingstone and Helsper 2008). However, research suggests that in Japan, there is a tendency for parents, particularly mothers, to control and/or surveil their children's activities. For example, in analyzing thirteen mothers' views on their children's mobile phone use in suburban Tokyo, Matsuda (2008) found that the primary reason for children's mobile phone ownership was so the mothers could monitor their children's whereabouts and/or coordinate their schedules when the children were commuting to and from school. As Spry (2012) points out, modern technologies have become a powerful site for parents to project their hopes and fears. Thus, although the material properties of personal mobile technologies offer potential for personalized and agentic learning experiences, the social aspect of adult monitoring complicates the autonomy-privacy paradox and constrains child agency. We argue that the agency paradox and socio-materiality offer a nuanced way of understanding the ensemble of social and material factors that feed into adults' aspirations and concerns about personalized technologies.

\subsection{Methodological Implications}

In alignment with previous research, we found focus group interviews a valuable technique. The interaction in each group allowed participants to share and discuss their personal and collective perspectives (Morgan 1996) and provided a safe environment in which to share and expand on each other's points. This was enhanced by participants' familiarity with and confidence in the Japanese second author, which contributed to trusting relationships where participants were confident to share their views openly and reflectively.

\subsection{Implications for Pedagogical Practice}

Understanding teachers' and designers' views on digital personalization and children's use of technologies is essential to identify and overcome the challenges of firmly embedding effective technology use in pedagogy, in ways that offer new avenues for children's agency. The paradoxical views held on personalized technologies must be recognized by teachers and designers alike, and responded to if digital technologies are to be used effectively in the classroom. Based on the insights provided by the participants in our focus group interviews we recommend that personalized technologies are implemented with caution and in ways that maximize support for children's agency whilst not compromising the privacy and security of children's personal data. While our study does not offer solutions to adult concerns for children's digital safety and security, it does point to areas where software designers would do well to consult extensively with teachers and researchers in the development of digital learning resources.

\subsection{Study Limitations}

The sample in our study was small and there was no longitudinal design to probe possible changes in participants' views over time, with different devices or over extended experience of personalized technology use. We did not compare the prevalence of the key themes across our participants or in relation to the participant characteristics. Future research could address these limitations and ask questions that further clarify the socio-material connections in adults' views on children's learning technologies. 
In conclusion, our study provides detailed insights into the complex nature of teachers' and software designers' attitudes towards children's use of personalized technologies. Japanese teachers and designers expressed their enthusiasm about the potential of digital personalized technologies to promote children's agency, but they were also concerned about children's privacy, particularly the safety and security of personal child data. We call this the 'agency paradox' and connect it to the theoretical perspectives on privacy/autonomy paradox noted in relation to personalization. The connection between socio-materiality and our findings is significant: there is a complex interplay of personal, socio-cultural and technological factors that frame teachers' and designers' often ambivalent perspectives on using personalized technologies with young children. The socio-material entanglement points to the need for further research into the assemblages of factors that bring to bear on technology use in contemporary early childhood education.

Acknowledgements Open Access funding provided by University Of Stavanger The authors would like to thank all the participating teachers and designers in the interviews. This study was funded by the Daiwa Anglo-Japanese Foundation (Small Grant number 10728/13096) and by the Economic and Social Research Council (Grant Number ES/N01779X/1).

Open Access This article is licensed under a Creative Commons Attribution 4.0 International License, which permits use, sharing, adaptation, distribution and reproduction in any medium or format, as long as you give appropriate credit to the original author(s) and the source, provide a link to the Creative Commons licence, and indicate if changes were made. The images or other third party material in this article are included in the article's Creative Commons licence, unless indicated otherwise in a credit line to the material. If material is not included in the article's Creative Commons licence and your intended use is not permitted by statutory regulation or exceeds the permitted use, you will need to obtain permission directly from the copyright holder. To view a copy of this licence, visit http://creativecommons.org/licenses/by/4.0/.

\section{References}

Aronson, J. (1995). A pragmatic view of thematic analysis. The Qualitative Report, 2(1), 1-3.

Åberg, E. S., Lantz-Andersson, A., \& Pramling, N. (2015). Children's digital storymaking-The negotiated nature of instructional literacy events. Nordic Journal of Digital Literacy, 10(03), 170-189.

Awad, N. F., \& Krishnan, M. S. (2006). The personalization privacy paradox: an empirical evaluation of information transparency and the willingness to be profiled online for personalization. MIS quarterly, $30,13-28$.

Barad, K. (2007). Meeting the universe halfway: Quantum physics and the entanglement of matter and meaning. Durham: Duke university Press.

Barnes, S. B. (2006). A privacy paradox: Social networking in the United States. First Monday, 11(9).

Berger, R. (2015). Now I see it, now I don't: Researcher's position and reflexivity in qualitative research. Qualitative Research, 15(2), 219-234.

Boyatzis, R. E. (1998). Transforming qualitative information: Thematic analysis and code development. Thousand Oaks: Sage.

Carlsson, M. A., Pramling, I., Wen, Q., \& Izumi, C. (1996). Understanding a tale in Sweden, Japan and China. Early Child Development and Care, 120(1), 17-28.

Chen, J.-Q., \& Chang, C. (2006). Using computers in early childhood classrooms: Teachers' attitudes, skills and practices. Journal of Early Childhood Research, 4(2), 169-188.

Chesney, T., Kanoh, H., \& Lawson, S. (2010). A cross cultural comparison of virtual pet companionship in the UK and Japan. Retrieved from: https://ideas.repec.org/p/bbr/workpa/14.html

Childs, P., \& Storry, M. (2003). Introduction: Britain in the modern world. In P. Childs \& M. Storry (Eds.), British Cultural Identities (pp. 15-25). London: Routledge.

Common Sense Media (2017) The Common Sense Census: Media Use by Kids Age Zero to Eight 2017, Available online from: https://www.commonsensemedia.org/research/the-common-sense-censu s-media-use-by-kids-age-zero-to-eight-2017

Dezuanni, M. (2015). The building blocks of digital media literacy: Socio-material participation and the production of media knowledge. Journal of Curriculum Studies, 47(3), 416-439. 
Dijkstra, A. (2014). The persuasive effects of personalization through: Name mentioning in a smoking cessation message. User Modeling and User-Adapted Interaction, 24(5), 393-411.

Domsch, S. (2013). Storyplaying: Agency and narrative in video games (Vol. 4). Berlin: Walter de Gruyter.

Dowling, M. (2006). Approaches to reflexivity in qualitative research. Nurse researcher, 13(3), 7-21.

Etikan, I., Musa, S. A., \& Alkassim, R. S. (2016). Comparison of convenience sampling and purposive sampling. American journal of theoretical and applied statistics, 5(1), 1-4.

Fake, H., \& Dabbagh, N. (2020). Personalized Learning Within Online Workforce Learning Environments: Exploring Implementations, Obstacles, Opportunities, and Perspectives of Workforce Leaders. Technology, Knowledge and Learning, 1-21

Fróes, I. C. G., \& Tosca, S. (2017). Playful Subversions: Young children and tablet use. European Journal of Cultural Studies, published online before print: https://doi.org/10.1177/1367549417705601

Foucault, M. (2003). Le pouvoir psychiatrique. Cours au Collège de France [Psychiatric power. Course at Collège de France]. 1973-1974. Paris: Gallimard/Seuil

Garzotto, F. (2008). Broadening children's involvement as design partners: from technology to. Paper presented at the Proceedings of the 7th international conference on Interaction design and children.

Gelfand, M. J., Raver, J. L., Nishii, L., Leslie, L. M., Lun, J., Lim, B. C., et al. (2011). Differences between tight and loose cultures: A 33-nation study. Science, 332(6033), 1100-1104.

Gromik, N. (2009). Japan-based CALL research: A literature review. OnCUE Journal, 3(1), 106-132. https ://hdl.handle.net/1959.11/14075

Gupta, A. (2014). Diverse early childhood education policies and practices: Voices and images from five countries in Asia. London: Routledge.

Hedegaard, M. (2009). Children's development from a cultural-historical approach: Children's activity in everyday local settings as foundation for their development. Mind, Culture, and Activity, 16(1), 64-82.

Hobbs, R. (2020). Propaganda in an Age of Algorithmic Personalization: Expanding Literacy Research and Practice. Reading Research Quarterly. Published online before print, https://doi.org/10.1002/rrq.301

Holloway, S. D. (2013). Contested childhood: Diversity and change in Japanese preschools. New York: Routledge.

Ifenthaler, D., Adcock, A. B., Erlandson, B. E., Gosper, M., Greiff, S., \& Pirnay-Dummer, P. (2014). Challenges for education in a connected world: Digital learning, data rich environments, and computerbased assessment-Introduction to the inaugural special issue of technology, knowledge and learning. Technology, knowledge and learning, 19(1-2), 121-126.

Ishigaki, E. H. (1991). The historical stream of early childhood pedagogic concepts in Japan. Early Child Development and Care, 75(1), 121-159.

Izumi-Taylor, S., Lee, Y. Y., \& Franceschini, L., III. (2011). A comparative study of childcare in Japan and the USA: who needs to take care of our young children? Early Child Development and Care, 181(1), 39-54.

Johri, A. (2011a). The socio-materiality of learning practices and implications for the field of learning technology. Research in Learning Technology, 19(3), 207-217.

Johri, A. (2011b). Sociomaterial bricolage: The creation of location-spanning work practices by global software developers. Information and Software Technology, 53(9), 955-968.

Kahn, P. (2009). Contexts for teaching and the exercise of agency in early-career academics: perspectives from realist social theory. International Journal for Academic Development, 14(3), 197-207.

Kalyanaraman, S., \& Sundar, S. S. (2006). The psychological appeal of personalized content in web portals: Does customization affect attitudes and behavior? Journal of Communication, 56(1), 110-132.

Kanoh, H. (2012). Influence of human beings on virtual pets. Paper presented at the e-society: IADIS International Conference, Berlin, Germany.

Kim, M. (2004). Teachers' philosophical orientation and practices: A study of novice preschool teachers in South Korea. Contemporary Issues in Early Childhood, 5(3), 276-292.

Knox, J., Williamson, B., \& Bayne, S. (2020). Machine behaviourism: Future visions of 'learnification' and 'datafication' across humans and digital technologies. Learning, Media and Technology, 45(1), 31-45.

Könings, K. D., Brand-Gruwel, S., \& Van Merriënboer, J. J. (2005). Towards more powerful learning environments through combining the perspectives of designers, teachers, and students. British Journal of Educational Psychology, 75(4), 645-660.

Könings, K. D., Seidel, T., \& van Merriënboer, J. J. (2014). Participatory design of learning environments: Integrating perspectives of students, teachers, and designers. Instructional Science, 42(1), 1-9.

Krumsvik, R. J. (2014). Teacher educators' digital competence. Scandinavian Journal of Educational Research, 58(3), 269-280.

Kuby, C. R. (2017). Why a paradigm shift of 'more than human ontologies' is needed: Putting to work poststructural and posthuman theories in writers' studio. International Journal of Qualitative Studies in Education, 30(9), 877-896. 
Kucirkova, N. (2017). Digital personalization in early childhood: Impact on childhood. London: Bloomsbury Publishing.

Kucirkova, N. (2019). Personalized education and technology. In C. Donohue (Ed.), Exploring key issues in early childhood and technology: Evolving perspectives and innovative approaches (pp. 71-79). New York/London: Routledge.

Kucirkova, N., \& Flewitt, R. (2020). The future-gazing potential of digital personalization in young children's reading: Views from education professionals and app designers. Early Child Development and Care, 190(2), 135-149.

Landerholm, E. (1996). Early childhood education in Japan and the United States: A comparison of regular education (kindergarten and daycare programs) and special education programs. Early Child Development and Care, 124(1), 33-47.

Li, J. (2012). Cultural foundations of learning: East and West. Cambridge: Cambridge University Press.

Lim, C., \& Torr, J. (2008). Teaching literacy in english language in Singaporean preschools: Exploring teachers' beliefs about what works best. Contemporary Issues in Early Childhood, 9(2), 95-106.

Livingstone, S., \& Helsper, E. J. (2008). Parental mediation of children's internet use. Journal of Broadcasting \& Electronic Media, 52(4), 581-599.

Marsh, J. (2011). Young children's literacy practices in a virtual world: Establishing an online interaction order. Reading Research Quarterly, 46(2), 101-118.

Marsh, J. (2017). The internet of toys: A posthuman and multimodal analysis of connected play. Teachers College record (1970), 119(15).

Marsh, J., Plowman, L., Yamada-Rice, D., Bishop, J., Lahmar, J., \& Scott, F. (2018). Play and creativity in young children's use of apps. British Journal of Educational Technology, 49(5), 870-882.

Masoumi, D. (2015). Preschool teachers' use of ICTs: Towards a typology of practice. Contemporary Issues in Early Childhood, 16(1), 5-17.

Mathews, G., \& White, B. (Eds.). (2012). Japan's changing generations: Are young people creating a new society? London: Routledge.

Matsuda, M. (2008). Children with Keitai: When Mobile Phones Change from "Unnecessary" to "Necessary". East Asian Science, Technology and Society: an International Journal, 2(2), 167-188.

Mazmanian, M., Orlikowski, W. J., \& Yates, J. (2013). The autonomy paradox: The implications of mobile email devices for knowledge professionals. Organization science, 24(5), 1337-1357.

MediaSmarts (2012) Young Canadiansin a Wired WorldPhase III, Available online from: https://mediasmart s.ca/sites/mediasmarts/files/pdfs/publication-report/full/YCWWIII-youth-parents.pdf

Mishra, P., \& Koehler, M. J. (2006). Technological pedagogical content knowledge: A framework for teacher knowledge. Teachers college record, 108(6), 1017.

Mitev, N., \& De Vaujany, F.-X. (2013). Materiality and space: organizations, artefacts and practices. London: Springer.

Morgan, D. L. (1996). Focus groups as qualitative research (Vol. 16). London: SAGE.

Neumann, M. M., Merchant, G., \& Burnett, C. (2018). Young children and tablets: the views of parents and teachers. Early Child Development and Care, 1-12.

Ofcom, (2018). Children and parents: media use and attitudes report 2018, Available online from Ofcom: https://www.ofcom.org.uk/research-and-data/media-literacy-research/childrens/children-and-parentsmedia-use-and-attitudes-report-2018.

Picton, I. (2017). Personalised print books and family literacy outcomes. London: National Literacy Trust.

Ronald, R., \& Hirayama, Y. (2009). Home alone: The individualization of young, urban Japanese singles. Environment and Planning A, 41, 2836-2854.

Rowsell, J. (2014). Toward a phenomenology of contemporary reading. Australian Journal of Language and Literacy, The, 37(2), 117.

Rubin, H. J., \& Rubin, I. S. (2011). Qualitative interviewing: The art of hearing data. Thousand Oaks: Sage.

Sato, N. (2003). Inside Japanese classrooms: The heart of education. London: Routledge.

Sato, T. (2008). Development of Software that Supports Young Children's Narrative Productions. Paper presented at the EdMedia: World Conference on Educational Media and Technology.

Selwyn, N. (2012). Education in a digital world: Global perspectives on technology and education. London: Routledge.

Spry, D. (2012). Fear and hope: The politics of childhood and mobile media. In The International Encyclopedia of Media Studies.

Taguma, M., Litjens, I., \& Makowiecki, K. (2012). Quality matters in early childhood education and care: Japan. OECD publication. Available online from: https://www.oecd-ilibrary.org/deliver/9789264176 621-en.pdf?itemId=/content/publication/9789264176621-en\&mimeType=application/pdf

Tayeb, M. (1994). Japanese managers and British culture: a comparative case study. International Journal of Human Resource Management, 5(1), 145-166. 
Tayeb, M. (2001). Conducting research across cultures: Overcoming drawbacks and obstacles. International Journal of cross cultural management, 1(1), 91-108.

Taylor, A. (2013). Reconfiguring the natures of childhood. London: Routledge.

Tobin, J., Hsueh, Y., \& Karasawa, M. (2009). Preschool in three cultures revisited: China, Japan, and the United States. Chicago: University of Chicago Press.

Triandis, H. C. (1995). Individualism and collectivism. New York: Westview Press: Routledge.

Triandis, H. C. (2017). Generic individualism and collectivism. In M. J. Gannon \& K. L. Newman (Eds.), The Blackwell handbook of cross-cultural management (pp. 16-45).

Triandis, H. C., \& Gelfand, M. J. (1998). Converging measurement of horizontal and vertical individualism and collectivism. Journal of personality and social psychology, 74(1), 118.

Vidal-Hall, C., Flewitt, R., \& Wyse, D. (2020). Early childhood practitioner beliefs about digital media: integrating technology into a child-centred classroom environment. European Early Childhood Education Research Journal., 28(2), 167-181. https://doi.org/10.1080/1350293X.2020.1735727.

Vignoles, V. L. (2018). The "common view", the "cultural binary", and how to move forward. Asian Journal of Social Psychology, 21(4), 336-345.

Yanow, D. (2015). Neither rigorous nor objective? Interrogating criteria for knowledge claims in interpretive science. In D. Yanow \& P. Schwartz-Shea (Eds.), Interpretation and Method (pp. 129-151). Routledge.

Yau, J. Y. K., \& Hristova, Z. (2018). Evaluation of an extendable context-aware "learning Java" app with personalized user profiling. Technology, knowledge and learning, 23(2), 315-330.

Yoshida, Y., Sekiya, D., Nakamura, T., Kanoh, M., \& Yamada, K. (2017). Hearing-Dog Robot to Wake People Up Using its Bumping Action. Paper presented at the International Conference on Computational Science/Intelligence \& Applied Informatics.

Zhang, S. \& Itoyama, K. (2018) The Japanese Smart Speaker Market, Available online from: https://voice bot.ai/2018/08/20/the-japanese-smart-speaker-market/

Publisher's Note Springer Nature remains neutral with regard to jurisdictional claims in published maps and institutional affiliations. 